C. Odenthal, F. Klasing, and T. Bauer, "Parametric study of the thermocline filler concept based on exergy," Journal of Energy Storage, vol. 17, pp. 56-62, Jun. 2018.

\title{
Parametric Study of the Thermocline Filler Concept Based on Exergy
}

\author{
Christian Odenthal $^{1}$, Freerk Klasing ${ }^{1}$ and Thomas Bauer $^{1}$ \\ ${ }^{1}$ German Aerospace Center (DLR), Linder Höhe, 51147 Cologne, Germany
}

\begin{abstract}
In this work, an extensive parametric study of the molten salt thermocline storage concept with filler is presented. The parametric study is coupled with an optimization routine, allowing a better comparison, since it finds only those storage configurations, which can directly substitute the two-tank system in a given power plant. Results show that, compared to the two-tank molten salt system, the thermocline technology achieves high exergetic efficiency at only slightly increased storage volume size and a huge decrease in salt inventory.
\end{abstract}

\section{Nomenclature}

$\begin{array}{rll}A_{0} & {\left[\mathrm{~m}^{2}\right]} & \text { cross sectional area } \\ d_{\text {part }} & {[\mathrm{m}]} & \text { particle diameter } \\ h & {[\mathrm{~h}]} & \text { specific enthalpy } \\ \Delta E_{\text {stor,nom }}^{\prime} & {[\mathrm{W}]} & \text { Initially available exergy } \\ \Delta E_{\text {stor }}^{\prime \prime} & {[\mathrm{W}]} & \text { regained exergy during discharge } \\ L_{\text {stor }} & {[\mathrm{m}]} & \text { storage tank length } \\ D_{\text {stor }} & {[\mathrm{m}]} & \text { storage tank diameter } \\ \dot{m} & {[\mathrm{~kg} / \mathrm{s}]} & \text { mass flow rate } \\ m & {[\mathrm{~kg}]} & \text { mass } \\ n & {[-]} & \text { integer number } \\ T & {\left[{ }^{\circ} \mathrm{C}\right]} & \text { temperature } \\ \Delta T_{\mathrm{e}} & {[\mathrm{K}]} & \text { permitted change in exit temperature } \\ x, y, z & {[\mathrm{~m}]} & \text { 1artesian axis direction } \\ \Delta p & {[\mathrm{bar}]} & \text { pressure loss } \\ s & {[\mathrm{~J} / \mathrm{kgK}]} & \text { specific entropy } \\ t & {[\mathrm{~s}]} & \text { time } \\ t_{\mathrm{e}}^{\prime} & {[\mathrm{s}]} & \text { storage time } \\ v & {[\mathrm{~m} / \mathrm{s}]} & \text { velocity } \\ V_{\text {stor }} & {\left[\mathrm{m}^{3}\right]} & \text { storage volume } \\ \dot{Q} & {[\mathrm{~W}]} & \text { thermal power } \\ \dot{Q}_{f}^{\prime \prime \prime} & {\left[\mathrm{W} / \mathrm{m}^{3}\right]} & \text { volumetric heat generation density } \\ \dot{Q}_{\mathrm{th}} & {[\mathrm{W}]} & \text { thermal power of the power block }\end{array}$

Special characters

$\begin{array}{lll}\alpha & {\left[\mathrm{W} / \mathrm{m}^{2} \mathrm{~K}\right]} & \text { heat transfer coefficient } \\ \varepsilon & {[-]} & \text { porosity } \\ \lambda & {[\mathrm{W} / \mathrm{mK}]} & \text { thermal conductivity } \\ \mu & {[\mathrm{Pas}]} & \text { dynamic viscosity } \\ \rho & {\left[\mathrm{kg} / \mathrm{m}^{3}\right]} & \text { density } \\ \Xi & {[-]} & \text { exergy regain } \\ \vartheta & {[-]} & \text { weighting factor }\end{array}$




\begin{tabular}{|c|c|}
\hline Subscripts & \\
\hline$e$ & end \\
\hline eff & effective \\
\hline$f$ & fluid \\
\hline in, out & inlet / outlet position \\
\hline init & initial value \\
\hline nom & nominal \\
\hline$s$ & solid \\
\hline set & set value \\
\hline th & thermal \\
\hline vol & volumetric \\
\hline$w t$ & weight \\
\hline
\end{tabular}

\section{Introduction}

Storing thermal energy in liquid molten salts provides an easy to handle and cost effective solution for thermal energy storage at high temperatures. The technology offers great potential for the energy transition in Germany. Examples are the improved use of waste heat from industrial processes or increasing the flexibility of power stations and cogeneration, as well as the conversion and storage of fluctuating surplus electricity from renewable energy sources. Proven technology, low cost salts as storage materials, excellent heat transfer rates and operation at ambient pressure are some of the key attributes for molten salt technology. By embedding a low cost solid filler material into the molten salt storage tank, further cost reductions of up to $33 \%$ can be achieved [1].

The thermocline concept with filler has already been demonstrated in the 80s in a large scale of 170 $\mathrm{MWh}_{\mathrm{th}}$ at the SolarOne power plant [2]. This system used thermal oil as HTF and rocks as filler material. Experimental results with molten salt, but in a smaller scale of $2.3 \mathrm{MWh}_{\mathrm{th}}$ have been presented by Sandia. In this test facility a ternary molten salt mixture $\left(44 \% \%_{\text {wt }} \mathrm{Ca}\left(\mathrm{NO}_{3}\right)_{2}\right.$, $12 \%_{\mathrm{wt}} \mathrm{NaNO}_{3}, 44 \%_{\mathrm{wt}} \mathrm{KNO}_{3}$, similar to Hitec XL) has been used along with quartizite rocks and silica sand at temperatures of up to $500^{\circ} \mathrm{C}$. During operation, part of the calcium nitrate transformed to calcium carbonate, particularly in the cold tank which had been open to atmosphere. However, the scaling was beneficial for the stability of the rocks, shielding them from degradation [3].

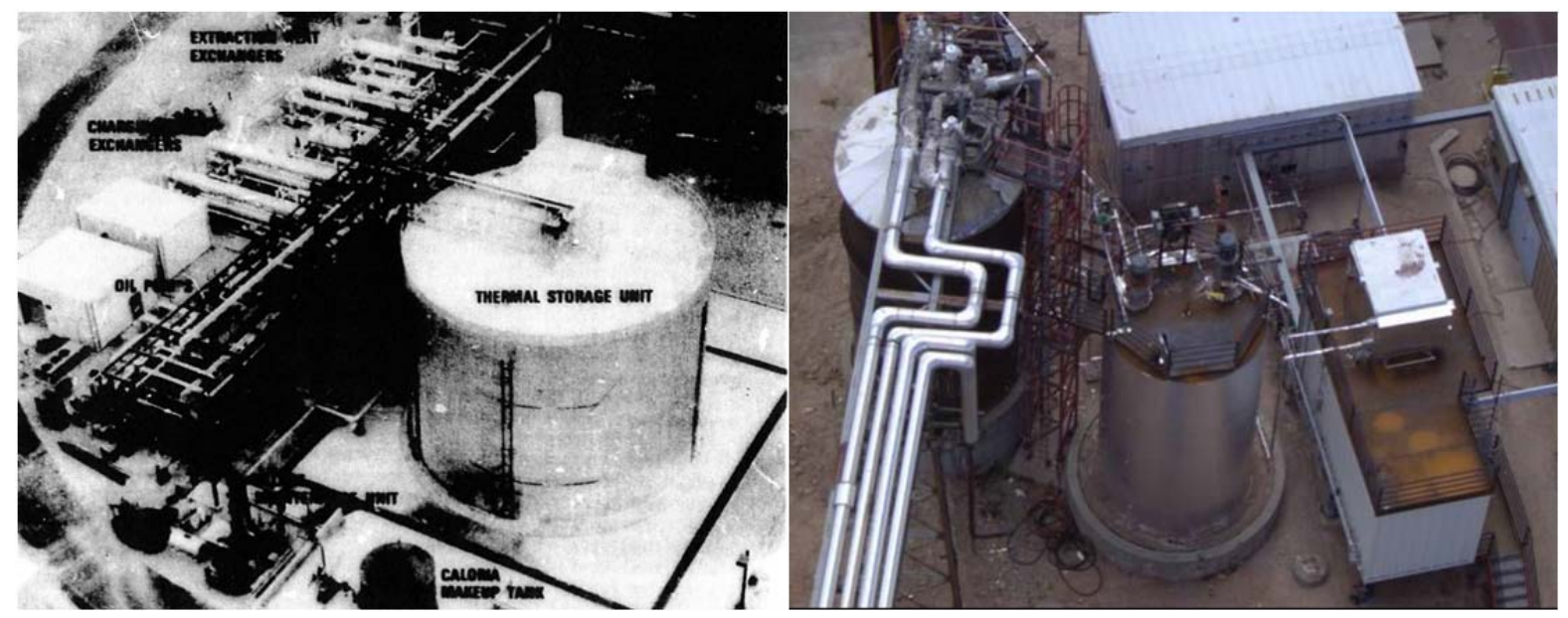

Fig. 1: Thermal oil thermocline storage tank of the SolarOne plant [2] (left); Molten salt thermal storage tank test facility at Sandia [4] (right)

A mid-sized experiment with $3 \mathrm{~m}$ height, $1 \mathrm{~m}$ diameter and thermal oil operating at up to $350{ }^{\circ} \mathrm{C}$ has been investigated at CEA [5]. CEA has also successfully demonstrated a complete plant, consisting of a fresnel collector, an organic rankine cycle (ORC) and a thermocline thermal storage with $30 \mathrm{~m}^{3}$ in volume [6]. In both cases thermal oil as HTF has been used. Another mid-sized experiment, similar to that of CEA, was developed in France as well: At the PROMES CNRS Laboratory in Odeillo, a 
thermocline tank with filler has been integrated to a parabolic trough loop with an ORC. The tank is 3 $\mathrm{m}$ in height and $1.3 \mathrm{~m}$ in diameter $\left(4 \mathrm{~m}^{3}\right)$ [7].

At DLR in cologne a large scale $\underline{T}$ est facility for thermal Energy Storage $\underline{\text { In molten }} \underline{\text { Salts }}$ (TESIS) has been set up. The volume of the storage tank is $22 \mathrm{~m}^{3}$ and can be equipped with three equally sized baskets, holding the filler material. An illustration of the interior is shown in the left picture of Fig. 2 . The storage tank can be supplied with molten salt at a maximum temperature of $560^{\circ} \mathrm{C}$ and a mass flow of $4 \mathrm{~kg} / \mathrm{s}$. Hot and cold molten salt are held by two separate storage tanks, visible on the right picture in Fig. 2. By using these storage tanks, a powerful auxiliary heater and cooler can be avoided, making the plant energy efficient. In fact, only $125 \mathrm{~kW}$ heating and cooling power are necessary for adjusting temperatures.

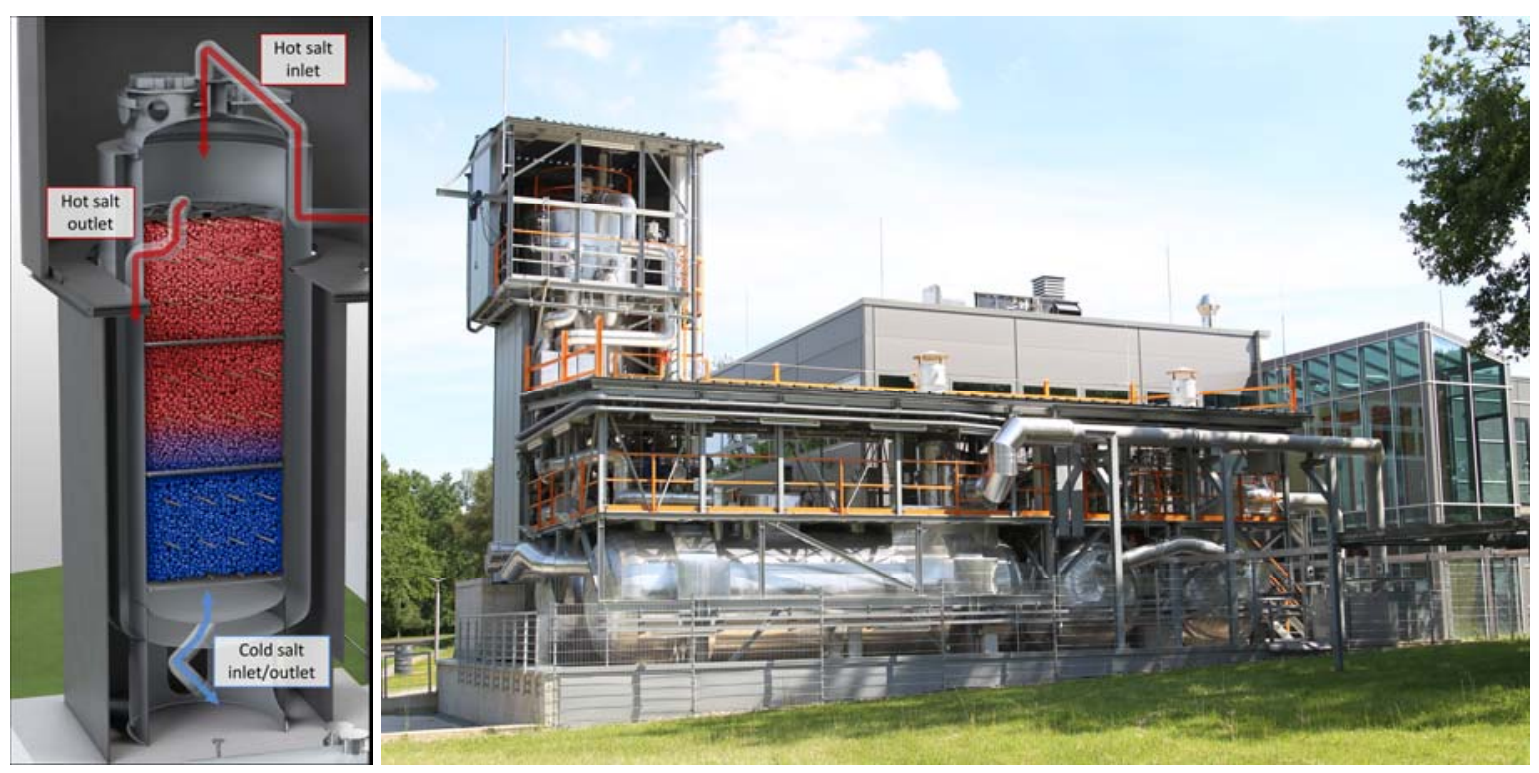

Fig. 2: Illustration of the thermocline filler storage tank of the TESIS facility (left) and picture of the plant (right)

Besides the experimental work, several theoretical investigations have been done. At CIEMAT simplified models for system simulations [9] and possible operation strategies [10] have been theoretically investigated. An analytic model developed at EEWRC has been used for the application of sensivity analysis for thermocline optimization [11].

As can be seen, technological challenges arise mainly from the chemical stability of the molten salt / filler system and the necessity in finding optimized operation strategies for such highly dynamic systems.

\section{Parametric Study of a Large Scale Thermocline System}

For the parametric study, a thermocline storage volume with solarsalt as HTF and basalt rocks as filler is considered. The thermophysical properties of solarsalt are taken from Bauer et al. [12], whilst properties for basalt can be found in Vosteen et al. [13]. For the attached process, a parabolic trough thermal power plant with $235 \mathrm{MW}_{\text {th }}$ nominal thermal power and a corresponding mass flow rate of $\dot{m}_{\mathrm{f}}=581.85 \mathrm{~kg} / \mathrm{s}$ is assumed. Two different cases are considered, one where the storage time during charging $\left(t^{\prime}{ }_{\mathrm{e}, \mathrm{set}}\right)$ is fixed to 8 hours and one where it is fixed to 12 hours. The superscript ' generally indicates the charging cycle, whereas " the discharging cycle.

The input values for the simulation are summarized in Table 1.

\section{Identification of Relevant Parameters}

For a thermal energy storage system, there are generally several major influencing parameters. All parameters are summarized in Table 1. 
From the system point of view, the permitted change in exit temperature has the most significant impact, since the system connected to the storage system must cope with the changing temperatures. However, there is also a significant impact on the utilization of the storage volume. From analytical solutions, it is known, that the thermocline region does not remain stable. Instead, it will grow with a rate which is proportional to square root of time [14]. In the moment of switching from charging to discharging (or vice versa), higher temperature differences between fluid and packing in the inlet region occur. These higher temperature differences cause an increased heat transfer. Thus, the packing can reach fluid temperature within a short distance along the flow direction. This shrinks the thermocline region in the beginning of a new charging or discharging period. Hence, the temperature differences between fluid and packing are directly linked to the permitted change in exit temperature $\left(\Delta T_{\mathrm{e}}\right)$. The highest differences occur, when the storage volume has been heated to uniform temperature beforehand, as it happens at the initial charging cycle. In this case, the shrinking effect on the thermocline region is the highest, whereas if $\Delta T_{\mathrm{e}}$ is small, the growth of the thermocline region is almost not affected. Fig. 3 illustrates this in an example calculation for the storage system of the TESIS test facility. The thermocline region is compact after the end of the first cycle, the only difference is, that in the case with 30 Kelvin $\Delta T_{\mathrm{e}}$, the region has moved a little further. After the $30^{\text {th }}$ cycle, however, the thermocline thickness has significantly gained, especially, if only small $\Delta T_{\mathrm{e}}$ are permitted. Looking at the graphs in the third column, in the case with 5 Kelvin $\Delta T_{\mathrm{e}}$, the thermocline can move only short distances, causing a poor utilization of the storage volume. If the same amount of energy should at given $\Delta T_{\mathrm{e}}$ be stored within, the bed length of the storage volume would have to be increased. This, in turn, would mean a larger tank, more fluid holdup, more thermal losses and eventually, higher costs. For the simulations, the permitted change in exit temperature $\Delta T_{\mathrm{e}}$ is varied in the stepping of 10, 20, 40 and 80 Kelvin.

Growth of the Thermocline Witdh
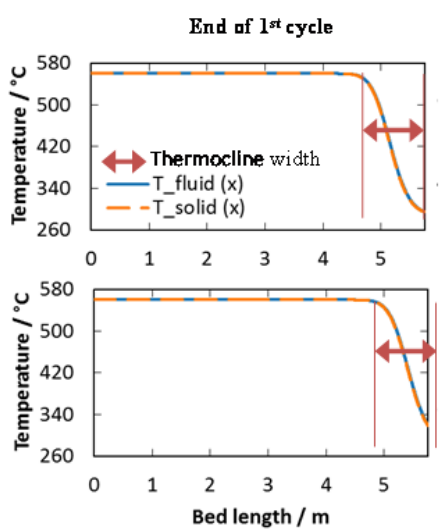
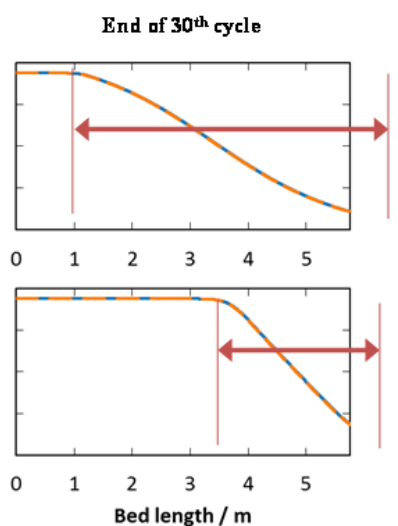

Impact on Utilization
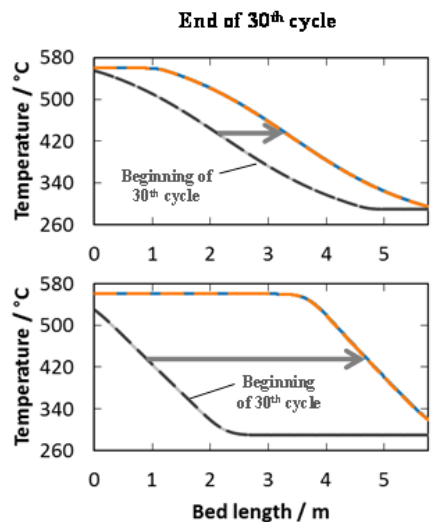

Fig. 3: Impact of the permitted change in exit temperature $\Delta \mathrm{Te}$ on the utilization of the thermocline storage system

During the day, there is a limited time where solar radiation is available. Hence, the charging time $\left(t_{\text {e,set }}^{\prime}\right)$, is another important parameter. In the present study, two cases with 8 hours and 12 hours charging time are investigated. Charging time has mainly an impact on storage size.

The shape of the storage tanks is directly affected by the cross sectional area $\left(A_{0}\right)$. Even though tank diameter and cross sectional area are linked via $A_{0}=\frac{\pi}{4} D_{\text {stor }}^{2}$, the latter parameter has been chosen, since flow speeds inside the packing scale linearly with the cross sectional area but squared with the tank diameter. The length of the storage volume $\left(L_{\text {stor }}\right)$ is subject to optimization for the emerging combinations of input parameters. In the study, a limitation of the flow length of $200 \mathrm{~m}$ has been set. This would be too long for a single tank, but multiple tanks being flown through consecutively could be an option.

Finally, particle diameter $\left(d_{\text {part }}\right)$ and porosity $(\varepsilon)$ are varied. Those parameters are quite convenient, since they almost do not affect the tank design. The particle diameter is varied between $1 \mathrm{~mm}$ up to $100 \mathrm{~mm}$. For a mono disperse packing a porosity of $40 \%$ can be achieved. By mixing different 
particle sizes, the porosity can be further reduced [15]. However, in this case pressure loss correlations and thermal models must be adopted accordingly, where the model is not capable for.

Table 1: Input values for parametric study

\begin{tabular}{rll}
\hline Description & Value & Unit \\
\hline Storage material & Basalt & - \\
Heat transfer fluid $(\mathrm{HTF})$ & Solarsalt & - \\
Storage time $\left(t_{\text {e,set }}^{\prime}\right)$ & 8,12 & $\mathrm{~h}$ \\
Thermal power $\left(\dot{Q}_{\mathrm{th}}\right)$ & 235 & $\mathrm{MW}_{\text {th }}$ \\
HTF mass flow $\left(\dot{m}_{\mathrm{f}}\right)$ & 581.85 & $\mathrm{~kg} / \mathrm{s}$ \\
Nominal inlet temperature $\left(T_{\text {in,nom }}^{\prime}\right)$ & 550 & ${ }^{\circ} \mathrm{C}$ \\
Nominal outlet temperature $\left(T_{\text {in,nom }}^{\prime \prime}\right)$ & 290 & ${ }^{\circ} \mathrm{C}$ \\
Flow length $\left(L_{\text {stor }}\right)$ & variable, max. 200 & $\mathrm{~m}$ \\
Permitted change in exit temperature $\left(\Delta T_{\mathrm{e}}\right)$ & $10,20,40,80$ & $\mathrm{~K}$ \\
Cross-sectional area $\left(A_{0}\right)$ & - & $\mathrm{m}^{2}$ \\
Particle diameter $\left(d_{\text {part }}\right)$ & $1-50$ & $\mathrm{~mm}$ \\
Porosity $(\varepsilon)$ & 40 & $\%$ \\
Permitted pressure loss $\left(\Delta p_{\text {max }}\right)$ & 0.5 & bar \\
\hline
\end{tabular}

For a realistic scenario, a maximum permitted pressure drop $\left(\Delta p_{\max }\right)$ of 0.5 bar for the bed is assumed. Also, if a single tank solution is favorited, tank dimensions should be somewhat near the state-of-theart with not exceeding $20 \mathrm{~m}$ in height.

\section{Computer Model}

To model the thermocline storage, a computer model is implemented which is based on the partial differential equations (PDE) of the fluid and solid temperature fields.

As for the fluid, the transient term for the change in inner energy, the transport of thermal energy, the conduction of thermal energy within the bed and the coupling with the solid are taken into account. When considering large storage volumes, heat losses can be neglected, since their influence is comparatively small.

The fluid PDE then reads

$$
\varepsilon \rho_{\mathrm{f}} C_{\mathrm{f}} \frac{\partial T_{\mathrm{f}}}{\partial t}=-\rho_{\mathrm{f}} c_{\mathrm{f}} v_{0, \mathrm{x}, \mathrm{f}} \frac{\partial T_{\mathrm{f}}}{\partial x}+\lambda_{\mathrm{eff}, \mathrm{x}, \mathrm{sf}} \frac{\partial^{2} T_{\mathrm{f}}}{\partial x^{2}}+\dot{Q}_{f}^{\prime \prime \prime}
$$

Here, $\varepsilon$ denotes the porosity, $\rho_{\mathrm{f}} c_{\mathrm{f}}$ the volumetric heat capacity of the fluid, $v_{0, \mathrm{x}, \mathrm{f}}$ the superficial flow velocity of the fluid and $\dot{Q}_{f}{ }^{\prime \prime \prime}$ the energy transfer from or to the solid. $\lambda_{\mathrm{eff}, \mathrm{x}, \mathrm{sf}}$ is the effective heat conductivity of the bed filled with salt. The effective conductivity of the solid and fluid can be considered as a parallel interconnection of their resistances, weighted by the respective porosities. Hence, the effective conductivity is

$$
\lambda_{\mathrm{eff}, \mathrm{x}, \mathrm{sf}}=\left(\frac{\varepsilon}{\lambda_{\mathrm{f}}}+\frac{1-\varepsilon}{\lambda_{\mathrm{s}}}\right)^{-1} .
$$

In terms of the solid, there is only the transient change in inner energy and a coupling term with the fluid, hence the solid PDE reads

$$
(1-\varepsilon) \rho_{\mathrm{s}} c_{\mathrm{s}} \frac{\partial T_{\mathrm{s}}}{\partial t}=\dot{Q}_{\mathrm{s}}^{\prime \prime \prime}
$$


The product $\rho_{\mathrm{s}} c_{\mathrm{s}}$ is the volumetric heat capacity of the solid and $\dot{Q}_{\mathrm{s}}{ }^{\prime \prime \prime}$ the coupling term, which is calculated from

$$
\begin{gathered}
\dot{Q}_{f}^{\prime \prime \prime}=-\dot{Q}_{s}^{\prime \prime \prime}=k_{\mathrm{vol}} \cdot\left(T_{\mathrm{s}}-T_{\mathrm{f}}\right), \\
\text { where } k_{\mathrm{vol}}=\frac{1}{\alpha_{\mathrm{vol}}}+\frac{2 \lambda}{5 \cdot d_{\mathrm{part}}}
\end{gathered}
$$

is the effective heat transfer coefficient. The second term in $k_{\mathrm{vol}}$ takes the resistance arising from the conductivity of the solid $\lambda$ into account and has been developed by Schmidt \& Willmott [16].

The film heat transfer $\alpha_{\mathrm{vol}}$ coefficient is calculated from a Nusselt-correlation derived by Wakao et al. [17]:

$$
N u=2+1.1 \cdot \operatorname{Pr}^{\frac{1}{3}} \cdot \operatorname{Re}_{\mathrm{part}, \mathrm{PB}}^{0,6}=\frac{a_{\mathrm{v}} \cdot \alpha_{\mathrm{vol}} \cdot d_{\mathrm{part}}}{\lambda_{\mathrm{f}}}=\frac{6(1-\varepsilon) \cdot \alpha_{\mathrm{vol}}}{\lambda_{\mathrm{f}}} .
$$

The specific surface per volume $a_{\mathrm{v}}$ is calculated from the porosity $\varepsilon$ and the average particle diameter $d_{\text {part }}$

$$
a_{\mathrm{v}}=\frac{6(1-\varepsilon)}{d_{\text {part }}}
$$

The pressure loss is calculated from Ergun's [18] equation, with the bed length $L_{\text {stor }}$ and the dynamic viscosity of the fluid $\mu_{\mathrm{f}}$ :

$$
\Delta p=\frac{L_{\text {stor }}}{d_{\text {part }}} \frac{(1-\varepsilon)}{\varepsilon^{3}}\left(\frac{150 \cdot(1-\varepsilon) \cdot \mu_{\mathrm{f}}}{\rho_{\mathrm{f}} v_{0, x, \mathrm{f}} \cdot d_{\text {part }}}+1,75\right) \rho_{\mathrm{f}} v_{0, \mathrm{f}}^{2}
$$

To solve the PDEs, a spatial discretization is applied, leading to a set of ordinary differential equations (ODEs), which are discretized by the "theta-rule" with respect to time. This leads to a system of linear dependent equations which can be described by

$$
\left(\overline{\bar{I}}+\vartheta \cdot \overline{\bar{M}}^{\mathbf{n + 1}}\right) \cdot \boldsymbol{T}^{\mathbf{n}+\mathbf{1}}=\left(\overline{\bar{I}}-(1-\vartheta) \cdot \overline{\bar{M}}^{\mathrm{n}}\right) \cdot \boldsymbol{T}^{\mathbf{n}}+\boldsymbol{b} .
$$

$\overline{\overline{\boldsymbol{I}}}$ is the identity matrix, $\overline{\overline{\boldsymbol{M}}}^{\mathbf{n}+\mathbf{1}}$ and $\overline{\overline{\boldsymbol{M}}}^{\mathbf{n}}$ are sparse band matrices, $\boldsymbol{T}^{\mathbf{n + 1}}$ and $\boldsymbol{T}^{\mathbf{n}}$ the vectors of the temperature field for the next and current time step, respectively, whilst vector $\boldsymbol{b}$ contains the boundary conditions. The scalar $\vartheta$ determines the weighting between implicit and explicit time discretization. For the current study it is set to $\vartheta=0.5$, which corresponds to the Crank-Nicholson scheme. The linear system is solved by the Matlab ${ }^{\circledR}$ routine mldivide which is part of a DLR in-house tool for sizing regenerator type thermal energy storages.

\section{Methodology of the Parametric Study}

To find the necessary storage length for a given set of input parameters, the model is coupled with an optimization routine. The optimization routine adopts the storage length in a way that the storage time during charging $\left(t^{\prime}{ }_{\mathrm{e}, \mathrm{set}}=\right.$ const $)$ is exactly met when the permitted change in exit temperature $\left(\Delta T_{\mathrm{e}}\right)$ is reached. An illustration of the scheme is shown in Fig. 4. 


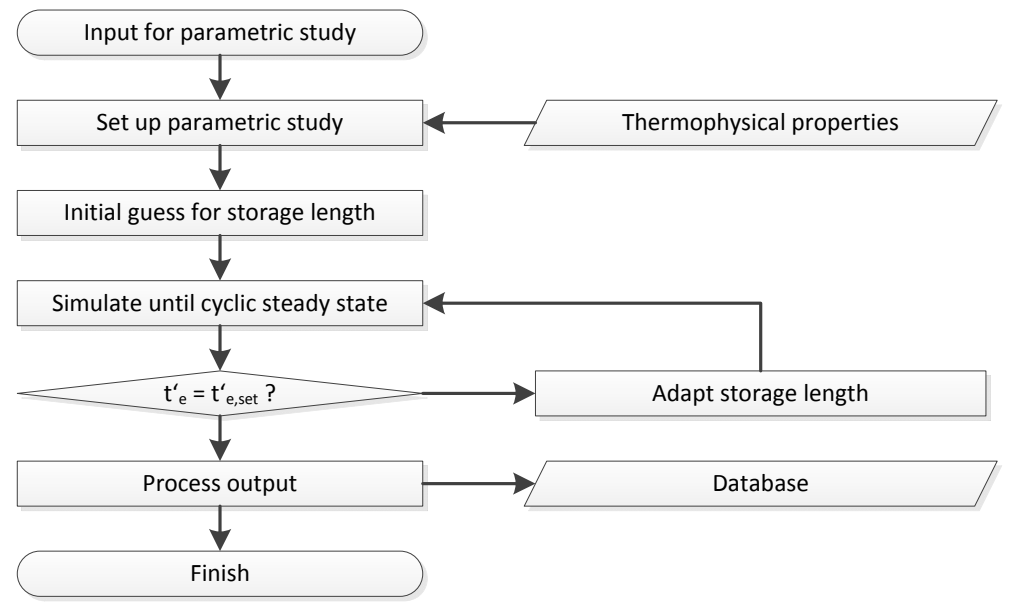

Fig. 4: Simplified scheme of the sizing tool

The methodology of adjusting the storage time for each configuration allows a straightforward comparison among each other, since every configuration now could be substituted with an existing two-tank molten salt storage system, having the same charging time $\left(t^{\prime}{ }_{\mathrm{e}}\right)$. Finally, a suitable quantity for the rating is necessary, which is described in the next section.

\section{Exergetic Rating of Storage Volumes}

The rating methodology is based on an exergetic efficiency which can be considered as an exergy regaining factor $\Xi$. Under nominal conditions (derived from the power cycle), a specific exergy stream $\dot{E}_{\text {nom }}^{\prime}$ during the charging time $t^{\prime}{ }_{\mathrm{e}}$ is available. The resulting nominal exergy $\Delta E_{\text {stornom }}^{\prime}$ is fed into the storage volume and results in an extracted exergy $\Delta E_{\text {stor }}^{\prime \prime}$ after discharging, as shown in Fig. 5.

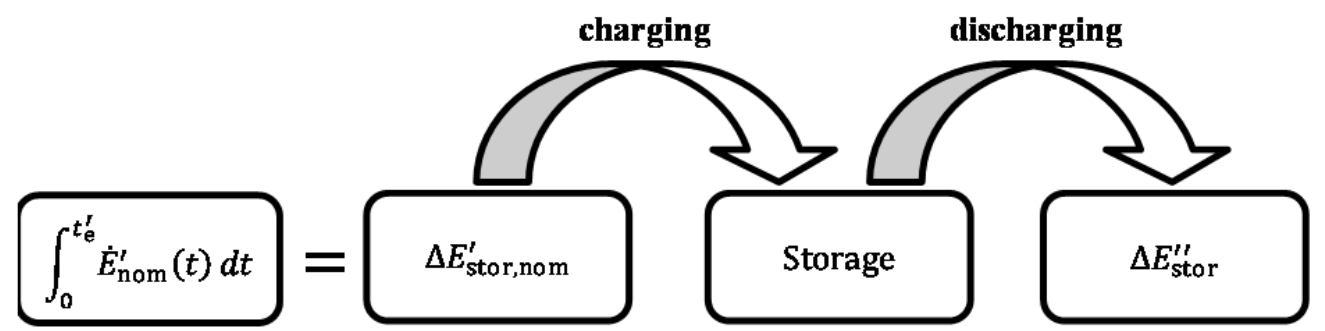

Fig. 5: Exergetic quantities for the rating of the storage volume

The exergy regaining factor $\Xi$ is then simply the quotient of extracted exergy $\Delta E_{\text {stor }}^{\prime \prime}$ and the nominal exergy $\Delta E_{\text {stor,nom }}^{\prime}$, as given by the following equation:

$$
\begin{aligned}
& \Xi=\frac{\Delta E_{\text {stor }}^{\prime \prime}}{\Delta E_{\text {stor,nom }}^{\prime}} \\
& =\frac{\int_{0}^{t_{\mathrm{e}}^{\prime \prime}} \dot{m}^{\prime \prime} \cdot\left[h\left(T_{\text {in,nom }}^{\prime \prime}\right)-h\left(T_{\text {out }}^{\prime \prime}(t)\right)-T_{\mathrm{u}} \cdot\left(s\left(T_{\text {in,nom }}^{\prime \prime}\right)-s\left(T_{\text {out }}^{\prime \prime}(t)\right)\right)\right] d t}{\int_{0}^{t_{\mathrm{e}}^{\prime}} \dot{m}^{\prime} \cdot\left[h\left(T_{\text {in,nom }}^{\prime}\right)-h\left(T_{\text {out nom }}^{\prime}\right)-T_{\mathrm{u}} \cdot\left(s\left(T_{\text {in,nom }}^{\prime}\right)-s\left(T_{\text {out,nom }}^{\prime}\right)\right)\right] d t} .
\end{aligned}
$$

In the equation, $h$ denotes the specific enthalpy, $s$ the specific entropy with $25^{\circ} \mathrm{C}$ as reference temperature und $T_{\mathrm{u}}$ the ambient temperature.

To contrast the exergy regaining factor $\Xi$, a second rating quantity is necessary. Due to the high share of the total costs caused by the molten salt [19], the total mass of the salt ( $\left.m_{\text {fluid }}\right)$ is considered here. 


\section{Settings of the computer model}

For the simulations, the number of nodes has been set to 250, which shows no significant influence on the results when increased. For the time step, a value of 60 seconds is chosen. The maximum number of charge and discharge cycles was set to a value of 100 . The residuum for assuming a cyclic steady state was set to a value of 0.001 Kelvin. The residuum is calculated from the difference of the mean temperature of the last discharging cycles. The calculation starts with a charging cycle from a uniform initial temperature of $290^{\circ} \mathrm{C}$. All settings are summarized in Table 2.

Table 2: Settings for the computer model

\begin{tabular}{rll}
\hline Description & Value & Unit \\
\hline Number of nodes $\left(n_{\text {nodes }}\right)$ & 250 & - \\
time step length $(d t)$ & 60 & $\mathrm{~s}$ \\
Number of maximum cycles $\left(n_{\text {max,cycles }}\right)$ & 100 & - \\
Residuum $($ res $)$ & 0.001 & $\mathrm{~K}$ \\
Initial temperature $\left(T_{\text {init }}\right)$ & 290 & ${ }^{\circ} \mathrm{C}$ \\
\hline
\end{tabular}

\section{Results of the Parametric Study}

In total 880 simulations are carried out, with the four parameters $\left(t_{\mathrm{e}, \mathrm{set}}{ }^{\prime}, \Delta T_{\mathrm{e}}, A_{0}, d_{\text {part }}\right)$ shown in Table 2 being varied. An illustration of the impacts of these parameters on the exergy regain and the necessary fluid mass is plotted in Fig. 7. As described beforehand, with increasing permitted change in exit temperature $\Delta T_{\mathrm{e}}$ the storage size reduces, which can be deducted from the lower necessary fluid mass. For the 12 hours storage time case, the onset of the temperature drop is clearly after 10 hours discharge time, which means that the exit temperature remains stable for more than $80 \%$ of the time. The progression of the exit temperatures is plotted in Fig. 6, left. A similar percentage of constant exit temperature applies to the case for 8 hours storage time, where the onset of the temperature drop is around 7 hours, as shown in Fig. 6, right.
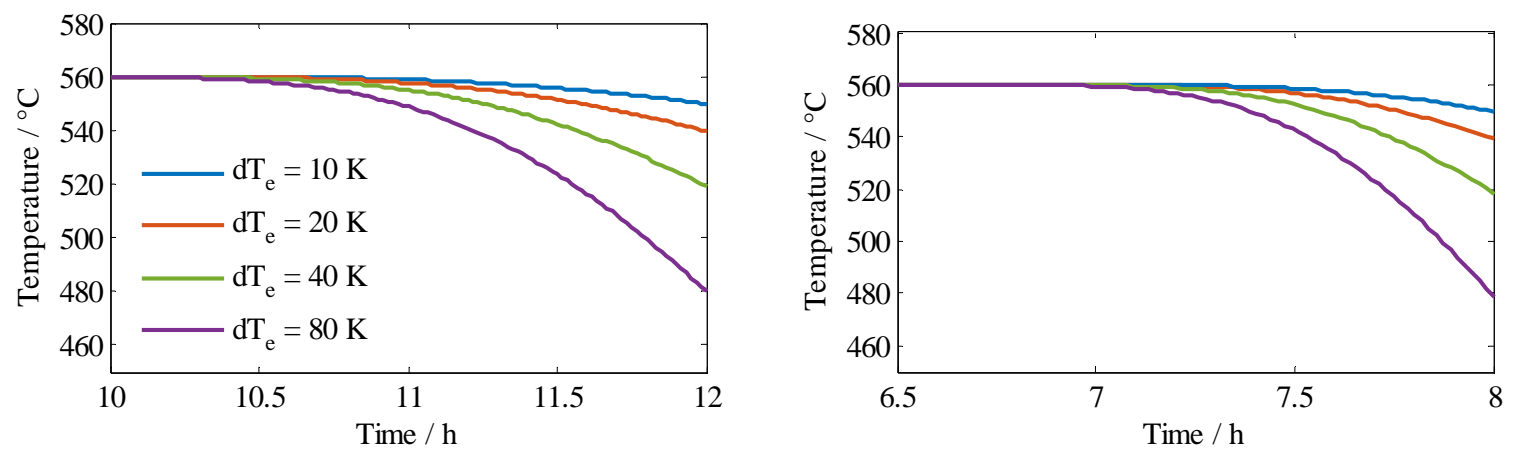

Fig. 6: Influence of permitted change in exit temperature on the progression of the exit temperature for 12 hours storage time (left) and 8 hours storage time (right)

Also, it can be seen from Fig. 7 that smaller particles are generally beneficial, since they provide better heat transfer, resulting in a potentially smaller thermocline. Through this, the period of constant exit temperature is longer, resulting in a higher efficiency. Regarding the cross sectional area, in most cases, there is only little impact on the storage performance, only for the highest efficiencies, there is a visible trend towards small cross sections. Regarding the pressure drop, the highest occurring pressure drop was roughly 7 bar.

Next, we want to exclude configurations with more than $20 \mathrm{~m}$ of the storage tank height and those having more than 1 bar of pressure drop. These configurations are marked by an " $x$ ". As can be seen, there are no configurations with a cross sectional area $A_{0}$ of less than $1000 \mathrm{~m}^{2}$ left, which corresponds to a tank diameter of about $36 \mathrm{~m}$. In terms of pressure drop, there are only a few configurations in the 
area between 1 and 7 bar, which correspond to a cross sectional area of less than $1000 \mathrm{~m}^{2}$ and therefore drop out anyway.

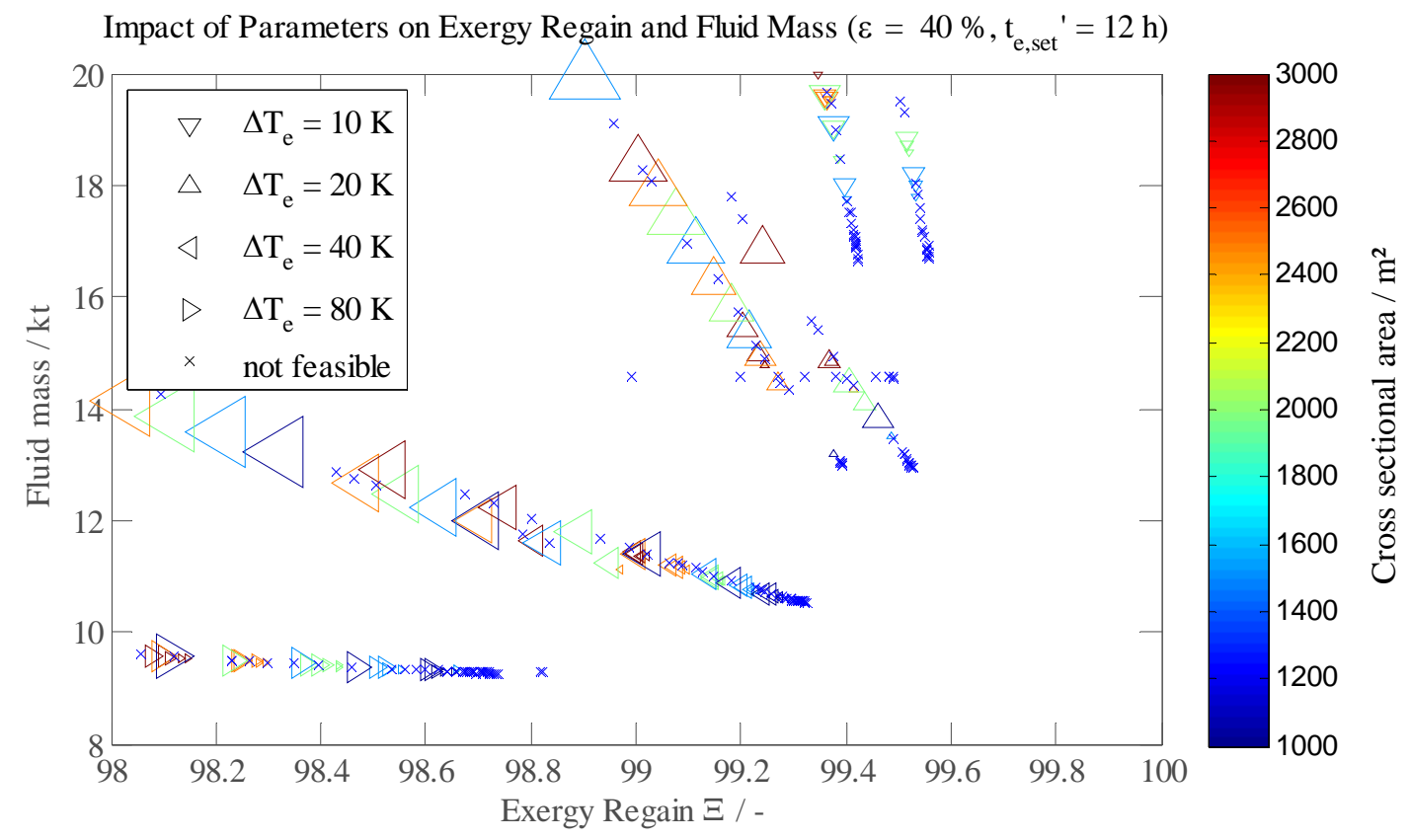

Fig. 7: 12 hour TCF storage system: Impact of parameter variations on exergy regain and fluid mass for different particle size $d_{\text {ref }}$ (marker size), cross sectional area $A_{0}$ (colorbar) and permitted change in exit temperature $\Delta T_{e}$ (marker style)

In the next figure, the results for 8 hours charging time $t_{\mathrm{e}, \mathrm{set}}{ }^{\prime}$ are shown. The storage size reduces proportional to the reduction in storage time. Due to the reduced size, there are also some configurations with only $500 \mathrm{~m}^{2}$ cross sectional area possible, which would be equivalent to a storage diameter of about $25 \mathrm{~m}$.

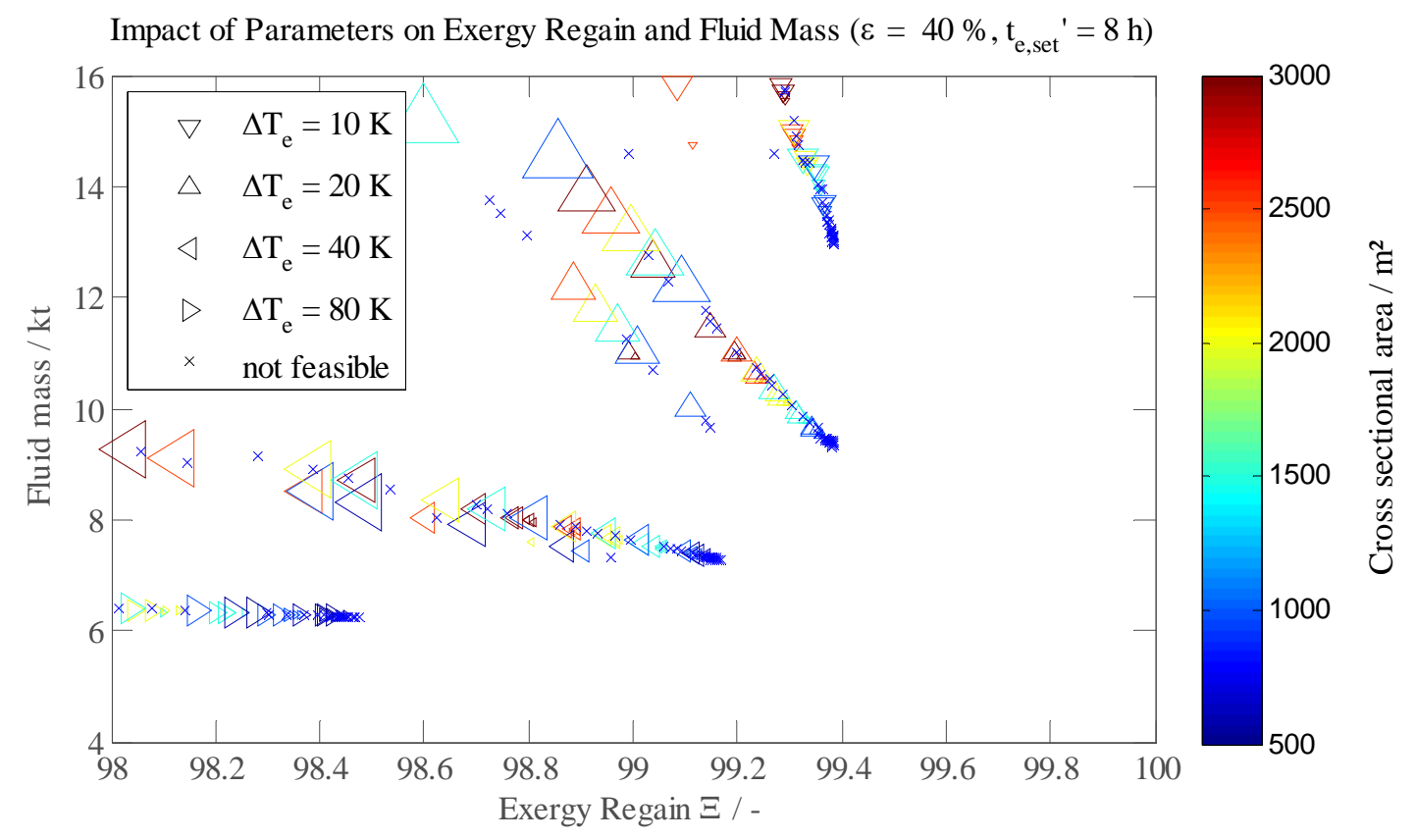

Fig. 8: 8 hour TCF storage system: Impact of parameter variations on exergy regain and fluid mass for different particle size $d_{\text {ref }}$ (marker size), cross sectional area $A_{0}$ (colorbar) and permitted change in exit temperature $\Delta \mathrm{T}_{\mathrm{e}}$ (marker style)

Looking closer at the feasible configurations, the following conclusions can be drawn: 
- Configurations with the lowest necessary fluid mass also have the highest exergy regain, when looking at one group of permitted change in exit temperature.

- Optimum cross sectional areas lie around $200 \mathrm{~m}^{2}$ to $600 \mathrm{~m}^{2}$, which would also result in storage tanks of at least $60 \mathrm{~m}$ to $25 \mathrm{~m}$ in height. A practical solution would rather have $1000 \mathrm{~m}^{2}$ with heights around $15 \mathrm{~m}$.

- The optimum particle diameter is the smallest possible in most cases.

- Permitted change in exit temperature has a significant impact on utilization, as stated beforehand.

- Exergy regain remains high, independently from storage time. The storage time directly affects the necessary lengths of the storage volume.

Table 3 shows the impact of the two parameters storage time and permitted change in exit temperature. Furthermore, it shows selected results for optimized storage configurations in terms of exergy regain $\Xi$ where $A_{0}$ and $d_{\text {part }}$ are optimized. The values are rounded to fit into the table. For comparison, the data of a two-tank molten salt storage system (2-T) is given as well.

Table 3: Optimum storage configurations for 8 hours and 12 hours storage time and a permitted change in exit temperature between $10 \mathrm{~K}$ and 80 Kelvin; Two-tank molten salt storage for comparison.

\begin{tabular}{|c|c|c|c|c|c|c|c|c|c|c|c|}
\hline System & & $\mathrm{C}, t_{e, s e}$ & $t^{\prime}=12$ & & $2-T$ & & $\mathbf{C}, \boldsymbol{t}_{e, s t}$ & $e t^{\prime}=8$ & & $2-T$ & \\
\hline $\begin{array}{r}\text { Permitted change in } \\
\text { exit temperature }\left(\Delta T_{\mathrm{e}}\right)\end{array}$ & 10 & 20 & 40 & 80 & $\mathbf{0}$ & 10 & 20 & 40 & 80 & $\mathbf{0}$ & $\mathbf{K}$ \\
\hline Exergy regain $(\Xi)$ & 99.55 & 99.38 & 99.27 & 98.63 & 100 & 98.37 & 99.36 & 99.11 & 98.35 & 100 & $\%$ \\
\hline Storage length ( $\left.L_{\text {stor }}\right)$ & 23.54 & 18.11 & 14.60 & 12.76 & 13.98 & 18.39 & 13.17 & 10.13 & 8.61 & 9.32 & $\mathrm{~m}$ \\
\hline Cross-sectional area $\left(A_{0}\right)$ & 1000 & 1000 & 1000 & 1000 & 1000 & 1000 & 1000 & 1000 & 1000 & 1000 & $\mathrm{~m}^{2}$ \\
\hline Storage Diameter ( $\left.D_{\text {stor }}\right)$ & 35.7 & 35.7 & 35.7 & 35.7 & 35.7 & 35.7 & 35.7 & 35.7 & 35.7 & 35.7 & $10^{3} \mathrm{~m}^{3}$ \\
\hline Particle diameter ( $\left.d_{\text {part }}\right)$ & 2 & 2 & 2 & 2 & - & 2 & 2 & 2 & 2 & - & $\mathrm{mm}$ \\
\hline Pressure loss $\left(\Delta p_{\mathrm{f}}\right)$ & 2225 & 1712 & 1380 & 1206 & - & 1738 & 1245 & 958 & 814 & - & $\mathrm{Pa}$ \\
\hline Fluid mass $\left(m_{\mathrm{f}}\right)$ & 17.16 & 13.20 & 10.64 & 9.30 & 24.20 & 13.4 & 9.60 & 7.38 & 6.28 & 16.14 & kt \\
\hline Solid mass $\left(m_{\mathrm{s}}\right)$ & 42.26 & 32.52 & 26.21 & 22.9 & 0 & 33.01 & 23.65 & 18.19 & 15.46 & 0 & $\mathrm{kt}$ \\
\hline
\end{tabular}

All configurations reach very high exergy regain rates. The reason for that is because pressure losses as well as driving temperature differences between molten salt and particles are very small. Due to the latter effect, the thermocline zone also remains very narrow, which causes exergy losses due to the temperature drop only at the very end of the cycles.

Since the two-tank system has no temperature differences and change in exit temperature, the exergy regain is $100 \%$. When compared to this, the thermocline with filler performs still very well. Because of the thermocline zone, the utilization of the thermocline storage volume is lower than the two-tank system. Interestingly, for a small permitted change in exit temperature $\left(\Delta T_{\mathrm{e}}\right)$, the increase in size can be more than $60 \%$. However, when $\Delta T_{\mathrm{e}}$ is getting larger, the utilization gets much better and finally, the tank size can be even reduced. The reason for this lies in the higher volumetric heat capacity of the basalt rocks.

When comparing the necessary fluid mass, the thermocline outperforms the two-tank system by a factor of roughly $2-3$. If the porosity can be further reduced, the necessary fluid mass could be further reduced.

\section{Summary}

The exergetic rating in the present study shows, that the thermocline filler storage causes only minor losses in exergy of less than one and a half percent when compared to the two-tank molten salt storage system. Simultaneously, the indicators for future investment costs are very promising: The tank size could even be reduced, whilst the amount of salt is decreased by a factor between $2-3$. These results were calculated under the assumption of constant boundary conditions from both power block and solar field. Further studies with detailed computer models of these components would allow a further refinement of the results. 


\section{Acknowledgements}

The authors thank the German Federal Ministry for Economic Affairs and Energy for the financial support given for this work in the MS-STORE project (Contract No. 0325497 A).

\section{Literature}

[1] C. S. Libby, "Solar Thermocline Storage Systems: Preliminary Design Study," 2010.

[2] S. E. Faas, L. R. Thorne, E. A. Fuchs, and N. D. Gilbertsen, "10 MWe Solar Thermal Central Receiver Pilot Plant: Thermal Storage Subsystem Evaluation Final report,” 1986.

[3] J. E. Pacheco, S. K. Showalter, and W. J. Kolb, "Development of a Molten-Salt Thermocline Thermal Storage System for Parabolic Trough Plants,” J. Sol. Energy Eng., vol. 124, no. 2, p. 153, 2002.

[4] D. a Brosseau, P. F. Hlava, and M. J. Kelly, "Testing Thermocline Filler Materials and Molten - Salt Heat Transfer Fluids for Thermal Energy Storage Systems Used in Parabolic Trough Solar Power Plants,” 2005.

[5] A. Bruch, J. F. Fourmigué, and R. Couturier, "Experimental and numerical investigation of a pilot-scale thermal oil packed bed thermal storage system for CSP power plant,” Sol. Energy, vol. 105, pp. 116-125, 2014.

[6] S. Rodat, A. Bruch, N. Dupassieux, and N. El Mourchid, "Unique Fresnel Demonstrator Including ORC and Thermocline Direct Thermal Storage: Operating Experience,” Energy Procedia, vol. 69, pp. 1667-1675, 2015.

[7] T. Fasquelle, Q. Falcoz, P. Neveu, F. Lecat, N. Boullet, and G. Flamant, "Operating results of a thermocline thermal energy storage included in a parabolic trough mini power plant," AIP Conf. Proc., vol. 1850, no. 1, 2017.

[8] J.-F. Hoffmann, T. Fasquelle, V. Goetz, and X. Py, "A thermocline thermal energy storage system with filler materials for concentrated solar power plants: Experimental data and numerical model sensitivity to different experimental tank scales," Appl. Therm. Eng., vol. 100, pp. 753-761, 2016.

[9] R. Bayón and E. Rojas, "Analytical function describing the behaviour of a thermocline storage tank: A requirement for annual simulations of solar thermal power plants," Int. J. Heat Mass Transf., vol. 68, pp. 641-648, Jan. 2014.

[10] M. Biencinto, R. Bayón, E. Rojas, and L. González, "Simulation and assessment of operation strategies for solar thermal power plants with a thermocline storage tank," Sol. Energy, vol. 103, pp. 456-472, 2014.

[11] A. M. Bonanos and E. V. Votyakov, "Sensitivity analysis for thermocline thermal storage tank design,” Renew. Energy, vol. 99, pp. 764-771, 2016.

[12] T. Bauer, N. Pfleger, N. Breidenbach, M. Eck, D. Laing, and S. (MPA) Kaesche, "Material aspects of Solar Salt for sensible heat storage,” Appl. Energy, vol. 111, pp. 1114-1119, 2013.

[13] H. Vosteen and R. Schellschmidt, "Influence of temperature on thermal conductivity, thermal capacity and thermal diffusivity for different types of rock," Phys. Chem. Earth, vol. 28, no. 911, pp. 499-509, 2003.

[14] A. V. Kuznetsov, "An analytical solution for heating a two-dimensional porous packed bed by a non-thermal equilibrium fluid flow,” Appl. Sci. Res., vol. 55, pp. 83-93, 1995.

[15] J. Latham, A. Munjiza, and Y. Lu, "On the prediction of void porosity and packing of rock particulates,” vol. 125, pp. 10-27, 2002.

[16] F. W. Schmidt and A. J. Willmott, Thermal energy storage and regeneration, 1st ed. Washington, D.C., USA: Hemisphere Publishing Corporation, 1981.

[17] N. Wakao and S. Kagei, Heat and mass transfer in packed beds. New York: Gordon and Breach Science Publishers Inc., 1982.

[18] S. Ergun and a. a. Orning, "Fluid Flow through Randomly Packed Columns and Fluidized Beds,” Ind. Eng. Chem., vol. 41, no. 6, pp. 1179-1184, Jun. 1949.

[19] B. Kelly and D. Kearney, "Thermal Storage Commercial Plant Design Study for a 2-Tank Indirect Molten Salt System,” National Renewable Energy Laboratory (NREL), 2004. 